\title{
Avaliação microbiológica de pés de frango destinados ao consumo humano
}

\author{
Microbiological evaluation of chicken feet intended for human \\ consumption
}

\author{
Ana Paula Dutra Resem Brizio ${ }^{1 *}$; Bruna Pereira de Salles ${ }^{2}$; Carlos Prentice ${ }^{3}$
}

Resumo

Os pés de frango são produtos com grande importância comercial no mercado asiático. Contudo, apesar do grande volume comercializado para estes países, o Brasil possui informações limitadas em relação à qualidade higiênico-sanitária destes produtos. $\mathrm{O}$ objetivo deste trabalho foi realizar uma avaliação da qualidade microbiológica de pés de frango congelados destinados ao consumo humano. Esta pesquisa foi desenvolvida em um matadouro-frigorífico, sob Serviço de Inspeção Federal, situado no estado do Rio Grande do Sul, durante o período de janeiro a dezembro de 2011. Um total de 98 amostras de pés de frango congelados foram analisadas quanto a presença de Salmonella spp., contagem total de bactérias mesófilas, contagem de coliformes totais, coliformes termotolerantes, Escherichia coli, Staphylococcus coagulase positiva e Clostridium perfringens. Em torno de $99 \%$ das amostras analisadas estavam dentro dos padrões estabelecidos pela legislação sanitária brasileira e chinesa (maior importador mundial) para carne de frango in natura. Desta forma, podemos concluir que as amostras de pés de frango congeladas apresentaram qualidade microbiológica satisfatória, não representando risco a saúde dos consumidores. Palavras-chave: Análise microbiológica, pés de frango, padrão legal, qualidade higiênico-sanitária

\begin{abstract}
Chicken feet are products with great commercial importance for the eastern markets. Although Brazil is a large exporter of these products to those markets, little information is available on the sanitary quality of these products. The objective of this study was to evaluate the microbiological quality of frozen chicken feet for human consumption. This study was developed in a slaughterhouse under Federal Inspection, located in the state of Rio Grande do Sul. A total of 98 samples of frozen chicken feet were analyzed, between January and December 2011, for the detection of Salmonella spp., total count of mesophilic bacteria, total coliforms, fecal coliforms, Escherichia coli, Staphylococcus coagulase positive and Clostridium perfringens. About $99 \%$ of the results were within the microbiological standards established by the Chinese (world's largest importer) and Brazilian legislation for raw chicken meat. Thus, we conclude that the samples of frozen chicken feet showed satisfactory microbiological quality and no risk to consumer health.
\end{abstract}

Key words: Microbiological analysis, chicken feet, legal standards, sanitary quality

\footnotetext{
${ }^{1}$ Discente de Doutorado em Engenharia e Ciência de Alimentos, Universidade Federal do Rio Grande, FURG, Rio Grande, RS. E-mail: anabrizio@yahoo.com.br

${ }^{2}$ Médica Veterinária, Termo de Cooperação Técnica da Prefeitura de Lajeado, Lajeado, RS. E-mail: brunasalles@gmail.com

${ }^{3}$ Prof. Associado, Universidade Federal do Rio Grande, FURG, Rio Grande, RS. E-mail: dqprent@furg.br

* Autor para correspondência
} 


\section{Introdução}

O Brasil produziu, em 2012, cerca de 12,65 milhões de toneladas de carne de frango, configurando-se o terceiro maior produtor mundial e o primeiro em exportação (UBABEF, 2013). Para assegurar estes mercados, a indústria deve ser cada vez mais competitiva e diversificada em seus produtos, procurando atender os consumidores com qualidade e preço. Neste contexto, o aproveitamento dos pés de forma lucrativa é fundamental, porque representam uma porção importante no peso final da ave (SANTOS, 2010).

Os pés de frango são exportados como cortes para vários países, sendo os mercados orientais os que se destacam atualmente em relação à comercialização destes produtos. Estes cortes possuem grande importância comercial e são considerados verdadeiras iguarias da culinária asiática (RODRIGUES, 2008).

Segundo a Portaria n²10/98 do Ministério da Agricultura, Pecuária e Abastecimento (MAPA) (BRASIL, 1998) o processamento tecnológico de obtenção de pés de frango congelados tem seu inicio no corte da perna, entre o metatarso e a tíbia, e sua separação da carcaça. As unhas e a fina cutícula amarela que os cobre são removidas, através de tratamento térmico denominado escaldagem. Após este processo, partem para o resfriamento realizado em tanques contínuos (chiller) contendo água gelada e gelo. Depois, são embalados e congelados em túneis de congelamento. De acordo com Unece (2007) o controle sobre todas as etapas pelas quais o produto passa garante sua qualidade higiênicosanitária.

Não há legislação específica que regulamente análises microbiológicas para pés de frango no Brasil, sendo assim, são utilizados os padrões recomendados para a carne de frango in natura (SANTOS et al., 2011). A Resolução da Diretoria Colegiada (RDC) $n^{\circ} 12$ da Agência Nacional de Vigilância Sanitária (BRASIL, 2001) estabelece padrões microbiológicos sanitários para alimentos, e a carne de frango in natura resfriada ou congelada, em carcaça inteira ou cortes, para ser comercializada deve obedecer apenas ao limite para Coliformes termotolerantes a $45^{\circ} \mathrm{C}$, considerando o produto inaceitável ao consumo quando o resultado ultrapassar $10^{4}$ Unidades Formadoras de Colônia (UFC) por grama de alimento.

No caso de fabricação de pés de frango destinados a República Popular da China, principal importador mundial, os produtos devem apresentar conformidade com a legislação sanitária chinesa para produtos avícolas in natura congelados (carcaças e cortes de frango), que estabelece a enumeração de bactérias aeróbias mesófilas $\left(\leq 5,0 \times 10^{5} \mathrm{UFC} / \mathrm{g}\right)$, coliformes totais $\left(\leq 5,0 \times 10^{3} \mathrm{UFC} / \mathrm{g}\right)$ e detecção de Salmonella spp. (ausência em 25g) (USDA/FAS, 2006).

Apesar do grande volume comercializado de pés de frango, atualmente há informações limitadas em relação à qualidade higiênico-sanitária destes produtos no Brasil. Portanto, o objetivo deste trabalho foi realizar uma avaliação da qualidade microbiológica de pés de frango destinados ao consumo humano.

\section{Material e Métodos}

Esta pesquisa foi desenvolvida em um matadouro-frigorífico, sob Serviço de Inspeção Federal, situado no estado do Rio Grande do Sul, durante o período de janeiro a dezembro de 2011, totalizando a coleta de 98 amostras de pés de frango congelados.

Os produtos foram colhidos após a etapa de congelamento em embalagens originais da empresa produtora (pacotes de $1 \mathrm{~kg}$ de produto). Duas coletas semanais foram realizadas durante doze meses de estudo. Após a coleta de cada amostra, as mesmas eram imediatamente acondicionadas em caixas térmicas com gelo para o envio ao laboratório.

A escolha dos micro-organismos neste estudo 
foi baseada na legislação brasileira e chinesa (BRASIL, 2001; USDA/FAS, 2006) e na literatura (JAY, 2005; USDA/FAS, 2006). Foram analisadas as bactérias aeróbias mesófilas, coliformes totais, coliformes termotolerantes $\left(45^{\circ} \mathrm{C}\right)$, Escherichia coli, Staphylococcus coagulase positiva Clostridium perfringens e Salmonella spp., conforme metodologia recomendada pela Instrução Normativa n62/2003 do Ministério da Agricultura, Pecuária e Abastecimento MAPA (BRASIL, 2003) e American Public Health Association (APHA, 2001). As análises microbiológicas foram realizadas em triplicata.

\section{Resultados e Discussão}

A Tabela 1 mostra os resultados microbiológicos de enumeração de bactérias aeróbias mesófilas, coliformes totais, coliformes termotolerantes, Escherichia coli, Staphylococcus coagulas positiva, e Clostridium perfringens, indicando a contagem mínima e máxima encontrada para cada microorganismo e a sua incidência média durante o período de estudo (doze meses).

Tabela 1. Resultados microbiológicos das amostras de pés de frango, expressos através da contagem mínima, máxima e média encontrada para cada micro-organismo durante o período de estudo.

\begin{tabular}{lccc}
\hline \multirow{2}{*}{ Micro-organismos } & \multicolumn{3}{c}{ Valores amostrais (UFC/g) } \\
\cline { 2 - 4 } & Contagem mínima & Contagem máxima & Contagem média \\
\hline Bactérias mesófilas & $\leq 1,0 \times 10^{1}$ & $5,3 \times 10^{4}$ & $4,3 \times 10^{3}$ \\
Coliformes totais & $6,1 \times 10^{1}$ & $2,1 \times 10^{4}$ & $1,2 \times 10^{3}$ \\
Coliformes a $45^{\circ} \mathrm{C}$ & $\leq 1,0 \times 10^{1}$ & $7,4 \times 10^{3}$ & $2,1 \times 10^{2}$ \\
E. coli & $\leq 1,0 \times 10^{1}$ & $7,0 \times 10^{3}$ & $1,5 \times 10^{2}$ \\
Staphylococcus coag. pos. & $4,8 \times 10^{1}$ & $4,1 \times 10^{3}$ & $1,0 \times 10^{3}$ \\
Clostridium perfringens & $\leq 1,0 \times 10^{1}$ & $2,0 \times 10^{2}$ & $1,8 \times 10^{1}$ \\
\hline
\end{tabular}

Fonte: Elaboração dos autores.

Embora a contagem de micro-organismos aeróbios mesófilos indique o grau de deterioração de alimentos, a legislação brasileira não estabelece padrão para estes organismos. A legislação da China, maior importador mundial de pés de frango, considera fora das condições higiênico-sanitárias ideais os produtos avícolas que ultrapassam contagens de $5,0 \times 10^{5} \mathrm{UFC} / \mathrm{g}$ para este grupo de bactérias (USDA/FAS, 2006). Assim, considerando esse índice, todas as amostras analisadas apresentaram-se conformes, com valor médio de contagem de $4,3 \times 10^{3} \mathrm{UFC} / \mathrm{g}$.

Os resultados de enumeração de bactérias mesófilas obtidos neste estudo foram semelhantes aos encontrados por Santos et al. (2011), os quais avaliaram microbiologicamente pés de frango em diversas etapas do processo produtivo de um matadouro-frigorífico, e obtiveram contagens em torno de $7,0 \times 10^{3} \mathrm{UFC} / \mathrm{g}\left(4,0 \log _{10} \mathrm{UFC} / \mathrm{g}\right)$ para os produtos após congelamento.

Os valores máximos detectados nas análises de coliformes totais e E.coli foram de $2,1 \times 10^{4}$ e $7,0 \times 10^{3} \mathrm{UFC} / \mathrm{g}$, respectivamente. Considerando o limite para coliformes totais de $\leq 5,0 \times 10^{3} \mathrm{UFC} / \mathrm{g}$ regulamentado na legislação sanitária chinesa, somente uma amostra (1/98) apresentou contagem acima desse limite. Contagens mais elevadas foram encontradas por Leite e Franco (2006), os quais analisaram a presença de coliformes totais e E.coli em cortes congelados de frango, com resultados

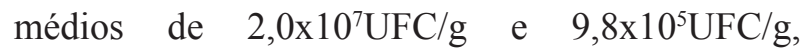
respectivamente. Os autores atribuíram as altas contagens a condições sanitárias inadequadas durante o processamento dos produtos analisados, 
já que, das 13 amostras positivas para E. coli, nove (69\%) haviam sido adquiridas em abatedouros clandestinos, evidenciando que os cuidados com as práticas higiênicas muitas vezes são negligenciados, confirmando o perigo em potencial para os consumidores deste tipo de carne e a necessidade de uma inspeção sanitária eficiente.

Ao observar os resultados de coliformes termotolerantes $\left(45^{\circ} \mathrm{C}\right)$, pode-se constatar que todas as amostras analisadas estavam em conformidade com o padrão nacional em carne de frango (BRASIL, 2001), de $\leq 10^{4} \mathrm{UFC} / \mathrm{g}$, o único existente no Brasil, já que não há uma legislação específica para pés de frango de corte. Segundo Kornacki e Johnson (2001), baixas contagens destes micro-organismos em produtos tratados termicamente demonstram que o processamento foi suficiente para inativar as bactérias vegetativas presentes no alimento.

A pesquisa de Staphylococcus spp. é realizada porque este micro-organismo pode causar intoxicação alimentar e também por ser considerado um indicador de higiene (PORTO et al., 2000). Estudos relatam que são necessárias entre $10^{5}$ e $10^{6}$ unidades formadoras de colônias de Staphylococcus por grama de alimento para que a toxina seja formada em níveis capazes de provocar intoxicação (BARBUT, 2002, FRANCO; LANDGRAF, 2005). Atendendo esta faixa, nenhuma amostra, no dia de fabricação avaliada, poderia representar risco à saúde do consumidor, caso a cepa fosse enterotoxigênica, já que, as contagens obtidas foram inferiores a $4,1 \times 10^{3} \mathrm{UFC} / \mathrm{g}$.

Embora Clostridium perfringens possa causar toxi-infecções comumente associadas à ingestão de produtos cárneos derivados de bovinos e aves, não existe um padrão oficial para este micro-organismo em carne de frango. Segundo Songer (2010), são necessárias contagens acima de $10^{5} \mathrm{UFC} / \mathrm{g}$ para que toxinfecções ocorram em seres humanos. Assim, considerando essa contagem, todas as amostras apresentaram resultados inferiores para este organismo. Cabe salientar, que as contagens nas amostras de pés de frango para Clostridium perfringens foram semelhantes em todo o período

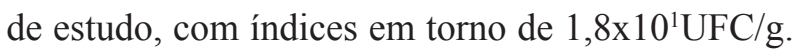
De acordo com Forsythe (2002), o tratamento térmico realizado durante o processo de obtenção dos produtos, aliado as baixas temperaturas de armazenamento, poderia justificar a dificuldade de crescimento deste micro-organismo nas amostras.

A Salmonella é um dos mais importantes patógenos mundialmente distribuídos associado à carne de frango e seus produtos derivados (BRYAN; DOYLE, 1995). No entanto, todas as amostras apresentaram-se negativas quanto à presença desta bactéria. Resultados diferentes foram descritos por Santos et al. (2011), os quais detectaram Salmonella spp. em 5,3\% das amostras pés de frango congeladas provenientes de um matadourofrigorífico localizado no Estado de Minas Gerais.

Vários estudos têm encontrado alta incidência de Salmonella spp. em carcaças de frango resfriadas e congeladas, com resultados que variam de 12 até 59\% de positividade (FUZIHARA; FERNADES; FRANCO, 2000; CARVALHO; CORTEZ, 2005; REITER et al., 2007; CHEN et al., 2010; BORSOI et al., 2010). Assim, apesar da ausência do patógeno nas amostras analisadas, a variação dos resultados entre outros estudos, bem como, o risco à saúde dos consumidores associado à presença desse micro-organismo, torna relevante o contínuo monitoramento.

Os resultados das análises microbiológicas apontam para a utilização eficaz das Boas Práticas de Fabricação (BPF's) durante as etapas de obtenção dos pés de frango no abatedouro em estudo. Trabalhos realizados por outros pesquisadores indicam reduções significativas da carga bacteriana nos processos que seguem as BPF's durante a elaboração dos produtos. Juneja, Marks e Mohr (2003) observaram que a manutenção de parâmetros adequados durante a escadalgem, como temperatura da água acima de $71^{\circ} \mathrm{C}$ é suficiente para reduzir 7,0 $\log 10$ de Salmonella spp. em pés de frango, 
considerando o tempo de processamento de 28 segundos. Santos et al. (2011) encontraram uma redução de 92,31\%; 99,98\% e 99,99\% na ocorrência de Salmonella spp., bactérias aeróbias mesófilas e coliformes termotolerantes, respectivamente, após o processamento térmico $\left(65-70^{\circ} \mathrm{C}\right.$ durante 28 segundos) e congelamento (temperatura $-30^{\circ} \mathrm{C}$ ) de amostras de pés de frango.

\section{Conclusões}

Em torno de 99\% das amostras analisadas encontraram-se dentro dos padrões estabelecidos pela legislação sanitária brasileira e chinesa para carne de frango in natura. Desta forma, podemos concluir que as amostras de pés de frango congeladas apresentaram qualidade microbiológica satisfatória, não representando risco a saúde dos consumidores.

Cabe salientar, no entanto, que apesar dos baixos índices de contaminação verificados, pouco se conhece sobre a qualidade higiênico-sanitária de pés de frango elaborados no Brasil. Em se tratando de produtos destinados à alimentação humana, tornase necessário a implementação de uma legislação específica, a qual estabeleça padrões de qualidade próprios. Assim, os resultados deste estudo podem servir de suporte para o estabelecimento de análises e limites bacteriológicos oficiais para pés de frango de corte.

\section{Referências}

AMERICAN PUBLIC HEALTH ASSOCIATION APHA. Compendium of methods for the microbiological examination of foods. Washington. DC, 2001.676 p.

BARBUT, S. Poultry products processing: an industry guide. Boca Raton: CRC, 2002.

BORSOI, A.; MORAES, H. L. S.; SALLE, C. T. P.; NASCIMENTO, V. P. Número mais provável de Salmonella isoladas de carcaças de frango resfriadas. Ciência Rural, Santa Maria, v. 40, n. 11, p. 2338-2342, 2010.

BRASIL. Ministério da Agricultura Pecuária e Abastecimento. Portaria $\mathrm{n}^{\circ} 210$, de 10 de novembro de 1998. Aprova Regulamento técnico de inspeção tecnológica e higiênico - sanitária de carnes de aves. Diário Oficial [da] República Federativa do Brasil, Brasília, DF, 26 dez. 1998. Seção 1, p. 226-272, 1998.

Ministério da Agricultura, Pecuária e Abastecimento. Instrução Normativa $n^{0} 62$, de 26 de agosto de 2003. Aprova os Métodos analíticos oficiais para análises microbiológicas para o controle de produtos de origem animal e água. Diário Oficial [da] República Federativa do Brasil, Brasília, DF, 18 set. 2003. Seção 1, p. 21-32; 40-43; 51-67, 2003.

Ministério da Saúde. Resolução RDC n ${ }^{\circ}$, de 02 de janeiro de 2001. Aprova o Regulamento técnico sobre padrões microbiológicos para alimentos. Diário Oficial [da] República Federativa do Brasil, Brasília, DF, 10 jan. 2001. Seção 1, p. 46-53, 2001.

BRYAN, F. L.; DOYLE, M. P. Health risks and consequences of Salmonella and Campylobacter jejuni in raw poultry. Journal of Food Protection, Des Moines, v. 58 , n. 3, p. $326-344,1995$.

CARVALHO, A. C. F. B.; CORTEZ, A. L. L. Salmonella sp. em carcaças, carne mecanicamente separada, lingüiças e cortes comerciais de frango. Ciência Rural, Santa Maria, v. 35, n. 6, p. 1465-1468, 2005.

CHEN, M. H.; WANG, S. W.; HWANG, W. Z.; TSAI, S. J.; HSIH, Y. C.; CHIOU, C. S.; TSEN, H. Y. Contamination of Salmonella Schwarzengrund cells in chicken meat from traditional marketplaces in Taiwan, and comparison of their antibiograms with those of the human isolates. Poultry Science, Savoy, v. 89, n. 2, p. 359-365, 2010.

FORSYTHE, S. J. Microbiologia da segurança alimentar. São Paulo: Artmed, 2002.

FRANCO, B. D. G. M.; LANDGRAF, M. Microbiologia dos alimentos. São Paulo: Atheneu, 2005.

FUZIHARA, T. O.; FERNADES, S. A.; FRANCO, B. D. G. M. Prevalence and dissemination of Salmonella serotypes along the slaughtering process in Brazilian small poultry slaghterhouses. Journal of Food Protection, Des Moines, v. 63, n. 12, p. 1749-1753, 2000.

JAY, J. M. Microbiologia de alimentos. Porto Alegre: Artmed, 2005.

JUNEJA, V. K.; MARKS, H. M.; MOHR, T. Predictive thermal inactivation model for effects of temperature, sodium lactate, $\mathrm{NaCl}$, and sodium pyrophosphate on Salmonella serotypes in ground beef. Applied and Environmental Microbiology, Washington D.C, v. 69, n. 9, p. 5138-5156, 2003. 
KORNACKI, J. L.; JOHSON, J. L. Enterobacteriaceae, Coliforms and Escherichia coli as quality and safety indicators. In: ITO, K. F. Compendium of methods for the microbiological examination of foods. Ann Arbor: Sheridan Books, 2001. cap. 8, p. 69-82.

LEITE, A. M. O.; FRANCO, R. M. Coliformes totais e Escherichia coli em coxas de frango comercializados no Rio de Janeiro. Revista Brasileira de Ciências Veterinárias, Niterói, v. 13, n. 2, p. 80-83, 2006.

PORTO, A. C. S.; TÔRRES, R. C. O.; ILHA, E. C.; LUIZ, M. T. B.; SANTANA, E. S. Influência da composição da salmoura sobre os parâmetros físico-sensoriais e microbiológicos de filés de peito de frango marinados por imersão. Boletim do CEPPA, Curitiba, v. 18, n. 2, p. 141-150, 2000.

REITER, M. G. R.; FIORESE, M. L.; MORETTO, G.; LÓPEZ, M. C.; JORDANO, R. Prevalence of Salmonella in a poultry slaughterhouse. Journal of Food Protection, Des Moines, v. 70, n. 7, p. 1723-1725, 2007.

RODRIGUES, F. S. Estratégias mercadológicas da cadeia agroexportadora de frango de corte no Brasil. 2008. Dissertação (Mestrado em Agronegócios) - Departamento de Economia e Administração. Universidade Federal do Mato Grosso do Sul, Campo Grande.
SANTOS, F. F. Qualidade bacteriológica de pés de frango de corte em diferentes etapas do processo tecnológico. 2010. Dissertação (Mestrado em Medicina Veterinária) - Universidade Federal Fluminense, Niterói.

SANTOS, F. F.; AQUINO, M. H. C.; NASCIMENTO, E. R.; ABREU, D. L. C.; GOUVEA, R.; RODRIGUES, D. P.; REIS, E. M. F.; ARAUJO, M. S.; PEREIRA, V. L. A. Chicken feet bacteriological quality at 4 steps of technological processing. Poultry Science, Savoy, v. 90, n.12, p. 2864-2868, 2011.

SONGER, J. G. Clostridia as agents of zoonotic disease. Veterinary Microbiology, Barcelona, v. 140, n. 3-4, p. 399-404, 2010.

UNIÃO BRASILEIRA DE AVICULTURA - UBABEF. Relatório anual 2013. São Paulo, 2013. Disponível em: <http://www.abef.com.br/ubabef/publicacoes_ relatoriosanuais.php $>$. Acesso em: 09 ago. 2013.

UNITED NATIONS ECONOMIC COMMISSION FOR EUROPE - UNECE. Standard for chicken meat carcasses and parts. Genova: United Nations Publications, 2006. 58 p.

UNITED STATES DEPARTMENT OF AGRICULTURE / FOREIGN AGRICULTURAL SERVICE - USDA/FAS. 2006. Fresh and frozen poultry product standard. GAIN Report: CH6001. Disponível em: <http://www.fas. usda. gov/gainfiles/200601/146176574.pdf>. Acesso em: 20 ago. 2012. 